\title{
Design methodology for flexible energy conversion systems accounting for dynamic performance
}

\author{
Pierobon, Leonardo; Casati, Emiliano ; Casella, Francesco ; Haglind, Fredrik; Colonna, Piero
}

Published in:

Energy

Link to article, DOI:

10.1016/j.energy.2014.03.010

Publication date:

2014

Document Version

Early version, also known as pre-print

Link back to DTU Orbit

Citation (APA):

Pierobon, L., Casati, E., Casella, F., Haglind, F., \& Colonna, P. (2014). Design methodology for flexible energy conversion systems accounting for dynamic performance. Energy, 68, 667-679.

https://doi.org/10.1016/j.energy.2014.03.010

\section{General rights}

Copyright and moral rights for the publications made accessible in the public portal are retained by the authors and/or other copyright owners and it is a condition of accessing publications that users recognise and abide by the legal requirements associated with these rights.

- Users may download and print one copy of any publication from the public portal for the purpose of private study or research.

- You may not further distribute the material or use it for any profit-making activity or commercial gain

- You may freely distribute the URL identifying the publication in the public portal 


\title{
Design methodology for flexible energy conversion systems accounting for dynamic performance
}

\author{
Leonardo Pierobon $^{\mathrm{a}, *}$, Emiliano Casati ${ }^{\mathrm{b}, \mathrm{c}},{\text { Francesco } \text { Casella }^{\mathrm{d}} \text {, Fredrik Haglind }}^{\mathrm{a}}$, Piero Colonna ${ }^{\mathrm{b}}$ \\ ${ }^{a}$ Department of Mechanical Engineering, Technical University of Denmark \\ Building 403, DK-2800 Kgs. Lyngby, Denmark \\ ${ }^{b}$ Propulsion and Power, Delft University of Technology \\ Kluyverweg 1, 2629 HS Delft, The Netherlands \\ ${ }^{c}$ Dipartimento di Energia, Politecnico di Milano \\ via Lambruschini 4, 20156 Milano, Italy \\ ${ }^{d}$ Dipartimento di Elettronica, Informazione e Bioingegneria, Politecnico di Milano \\ Piazza Leonardo da Vinci 32, 20133 Milano, Italy
}

\begin{abstract}
This article presents a methodology to help in the definition of the optimal design of power generation systems. The innovative element is the integration of requirements on dynamic performance into the system design procedure. Operational flexibility is an increasingly important specification of power systems for base- and part-load operation. Thus, it is crucial to discard, in an early phase of the design process, plant configurations which feature unacceptable dynamic performance. The test case is the preliminary design of an off-grid power plant serving an off-shore platform where one of the three gas turbines is combined with an organic Rankine cycle turbogenerator to increase the overall energy efficiency. At the core of the procedure is a stationary model, capable of performing the on-design thermodynamic cycle calculation, and the design of the components of the system. The results of these simulations are used within the framework of a multi-objective optimization procedure to identify a number of equally optimal system configurations. A dynamic model of each of these systems is automatically parameterized, by inheriting its parameters values from the design model. Dynamic simulations allow then to discriminate among the initial set of solutions, thus providing the designs that also comply with dynamic requirements. Keywords: Power plant dynamics, ORC, Flexible power systems, Multi-objective optimization
\end{abstract}

\footnotetext{
*Corresponding author

Email address: lpier@mek.dtu.dk (Leonardo Pierobon)
} 


\begin{tabular}{|c|c|c|c|}
\hline \multicolumn{4}{|c|}{ Nomenclature } \\
\hline$A$ & area $\left[\mathrm{m}^{2}\right]$ & $G A$ & genetic algorithm \\
\hline$F_{h}$ & fin height $[\mathrm{mm}]$ & GEN & electric generator \\
\hline$F_{p}$ & fin pitch $[\mathrm{mm}]$ & $G T$ & gas turbine \\
\hline$F_{t}$ & fin thickness $[\mathrm{mm}]$ & $H P C$ & high pressure compressor \\
\hline$H$ & head $[\mathrm{m}]$ & $H P T$ & high pressure turbine \\
\hline $\mathrm{Nu}$ & Nusselt number & $L P C$ & low pressure compressor \\
\hline$P$ & power $[\mathrm{kW}]$ & $L P T$ & low pressure turbine \\
\hline $\operatorname{Pr}$ & Prandtl number & ORC & organic Rankine cycle \\
\hline$R e$ & Reynolds number & $O T B$ & once through boiler \\
\hline$T$ & temperature $[\mathrm{K}]$ & $P I$ & proportional integral \\
\hline$U$ & overall heat transfer coefficient $\left[\mathrm{kW} \mathrm{m}{ }^{-2} \mathrm{~K}^{-1}\right]$ & $P T$ & pressure turbine \\
\hline$V$ & volume $\left[\mathrm{m}^{3}\right]$ & $R S D$ & relative standard deviation \\
\hline $\bar{J}$ & array of objective functions & $T U R$ & turbine \\
\hline $\bar{X}$ & array of variables & \multicolumn{2}{|c|}{ Greek letters } \\
\hline$\dot{m}$ & mass flow $\left[\mathrm{kg} \mathrm{s}^{-1}\right]$ & $\Delta$ & difference \\
\hline$b_{1}, b_{2}$ & parameters in Equation 6 & $\lambda$ & thermal conductivity $\left[\mathrm{W} \mathrm{m}^{-1} \mathrm{~K}^{-1}\right]$ \\
\hline$c$ & speed of sound $\left[\mathrm{m} \mathrm{s}^{-1}\right]$ & $\phi$ & exponent in Equation 6 \\
\hline$d$ & diameter $[\mathrm{m}]$ & $\rho$ & density $\left[\mathrm{kg} \mathrm{m}^{-3}\right]$ \\
\hline \multirow[t]{2}{*}{$h$} & heat transfer coefficient $\left[\mathrm{kW} \mathrm{m} \mathrm{m}^{-2} \mathrm{~K}^{-1}\right]$ or specific en- & \multicolumn{2}{|c|}{ Subscripts } \\
\hline & thalpy $\left[\mathrm{kJ} \mathrm{kg}^{-1}\right]$ & $b$ & baffle \\
\hline$l$ & length $[\mathrm{m}]$ & des & design \\
\hline$n$ & rotational speed $[\mathrm{rpm}]$ or exponent in Equation 5 & exh & exhaust gases \\
\hline$p$ & pressure [bar] & $f$ & fouling \\
\hline$p t$ & tube pitch & $i$ & inner \\
\hline$s$ & specific entropy $\left[\mathrm{kJ} \mathrm{kg}^{-1} \mathrm{~K}^{-1}\right]$ & $o$ & outer \\
\hline th & thickness $[\mathrm{m}]$ & $r$ & recuperator \\
\hline$u$ & velocity $\left[\mathrm{m} \mathrm{s}^{-1}\right]$ & $S$ & thermodynamic static state \\
\hline \multicolumn{2}{|c|}{ Abbreviations } & $T$ & thermodynamic total state \\
\hline$A C$ & alternating current & $t$ & tube \\
\hline$A M A$ & arithmetic mean average & th & throat \\
\hline$C C$ & combustion chamber & $w$ & metal wall \\
\hline \multicolumn{4}{|c|}{2} \\
\hline
\end{tabular}




\section{Introduction}

The recent liberalization of the electricity markets, along with the rapid expansion of the utilization of non-dispatchable renewable energy sources, such as wind and solar radiation, is stressing the necessity-opportunity of improving the flexibility of power generation systems [1]. New power technologies play therefore a significant role in providing such flexibility, and the electricity industry has acknowledged that this need will increase in the near future [2]. In the case of base-load power plants, changes to the scheduling procedures are leading to the latest combinedcycle gas turbine units being designed to operate efficiently and reliably under a wide range of rapidly varying conditions. Furthermore, both new coal and nuclear power plants are conceived with increased capability of operating under fast-load variations. In addition, older power stations are retrofitted in order to increase dynamic operation performance [3]. Operational flexibility is mandatory for off-grid power systems, and often preserving high energy conversion efficiency is also demanded. The electrification of remote areas is widely studied [4], together with the powering of industrial installations with systems operating in island [5].

In this context, system dynamic modeling and simulation is becoming a powerful design tool, especially if the level of detail of system and component models can be tuned to the design needs. In a recent work, Garcia et al. [6] investigated options to increase the robustness of energy networks, by simulating energy flow scenarios in which multiple forms of energy commodities, such as electricity and chemical products, may be exchanged. They studied the interactions between the grid and such advanced hybrid energy systems, by using dynamic models of various units and simulating their operation. Concerning the detailed study of advanced power systems, Zhu and Tomsovic [7] analyzed distributed combined cycle plants based on micro gas turbines and fuel cells, with the aim of reducing the costs related to ancillary services in a deregulated market. Alobaid et al. [8] developed a detailed model of a complete combined cycle, based on a steam Rankine unit cascaded to a gas turbine, in order to study and optimize its start-up procedure. Model-based control techniques for the same type of power plant are dealt with by Lopez-Negrete et al. [9].

Notwithstanding the mentioned advancements, to the knowledge of the authors the integration 
of dynamic performance analysis into the design process has not been considered yet. Discarding plant configurations featuring unacceptable dynamic performance (e.g., ramp-up and -down time) at a very early design phase can be very valuable. A traditional design approach, mainly aimed at increasing steady-state efficiency, might lead to systems that cannot comply with dynamic requirements, even if aggressive control strategies are pursued.

This work is aimed at the development of an automated preliminary design methodology in which system transient performance can be seamlessly evaluated together with other typical design requirements. In order to test the automated design tool, a relevant test case has been selected, namely the power plant of an off-shore oil and gas platform in the North Sea, operating off-grid. The problem consists in evaluating if it is possible to increase the efficiency of the three gas turbines (GTs), by installing an organic Rankine cycle (ORC) turbogenerator powered by the exhaust gases of one of the GT's, and still comply with stringent dynamic requirements.

This paper is structured as follows: the novel design methodology is outlined in Section 2, while Section 3 deals with the description of the case study. A detailed description of the models is presented in Section 4. The results are thus reported and discussed in Section 5. Concluding remarks are given in Section 6.

\section{Methodology}

The objective of this study is to develop and demonstrate a methodology for the preliminary design of power generation systems that integrates the fulfilling of dynamic requirements into the automated procedure. This goal is attained by performing two main steps.

In the first step, $N$ performance metrics are selected (e.g., the thermal efficiency, the overall system volume, the net present value), and a multi-objective optimization problem is solved in order to find a set of preliminary system designs which lead to optimal performance of the system at the rated operating point. The outcome is an $N$-dimensional Pareto front of system designs, which are optimal with respect to different objectives. In the second step, the dynamic performance of the system is assessed by simulating critical transients for each design on the Pareto front, and by verifying whether requirements and constraints involving dynamic variables are met or not. System designs which do not meet the dynamic requirements are discarded. 
The end-result of the procedure is a reduced set of optimal system designs complying with the trade-offs between different objectives, while ensuring proper system operation during critical transients. Based on this result, properly informed decisions about the final system design can be taken, thus avoiding the risk of discovering criticalities of transient operation at later project stages, i.e., during detailed design, or even commissioning, when corrective action might be very expensive or impossible.

\subsection{Multi-objective design optimization}

The design methodology utilized in the present work is described in detail by Pierobon et al. [10], applied to the exemplary case of an ORC power system. The design algorithm is implemented using the Matlab language; several new features were added to the previous version of the program (see Section 4.1.1). The design procedure is briefly summarized here for the sake of completeness.

First of all, boundary conditions, which hold for all designs, are defined. For example, in the case of an ORC heat recovery system, these are the mass flow rate, temperature and composition of the flue gas source, the selection of the working fluid, and the choice of the components, such as once-through boiler, shell and tube recuperator, and condenser. The thermodynamic states at the inlet and outlet of each component can thus be identified by applying basic energy and mass balances. Subsequently, the design of the plant equipment, e.g., the number, length, and diameter of tubes in the heat exchangers, or the turbine flow coefficient, is carried out automatically, ultimately leading to the evaluation of the chosen performance metrics. An iterative procedure then explores the design space, looking for optimal design configurations. The multi-objective optimization approach based on a genetic algorithm (GA) is adopted in this case.

Such design procedure takes care of the typical trade-offs, such as, for example, the one existing between the improvement of turbine performance, i.e., by reducing pressure losses in the recuperator (counter-pressure at the turbine discharge), and the reduction of thermodynamic irreversibility in the heat exchangers. The first goal might be obtained by reducing the heat transfer surface without altering the flow velocity. However, such surface reduction would lead to a deterioration of the heat exchange (larger irreversibility), due to the larger temperature difference 
between the hot and the cold stream.

\subsection{Assessment of dynamic performance}

The set-up of the second step of the design procedure requires to identify critical scenarios involving system transients, e.g. sudden load changes, load rejections, or unit trips. Requirements on critical variables are formulated, such as rise time, settling time, damping, maximum deviation, maximum or minimum allowed value during the transient, etc.

A nonlinear dynamic model of the plant based on first principles is needed, in such a way that it can be parameterized starting from the detailed design data obtained from the first step of the procedure. An effective way to build such model is to use the fully modular approach of the equation-based, object-oriented modeling language Modelica [11]. On the one hand, this allows to carry out the modeling task reliably and in a short time, by leveraging on existing and well-tested libraries of reusable component models. On the other hand, the equation-based approach of the language makes it possible to easily customize the models for the specific requirements of the design problem at hand.

In most cases, the system dynamics is the result of the interaction between the inherent plant dynamics and the control system action, with the controller often playing a crucial role. The definition of the design parameters cannot be complete without the values of the controller parameters. It is then necessary to define control system tuning criteria leading to desirable or optimal performance, which can be applied automatically given the specific values of the design parameters. The assessment of dynamic performance can then be carried out automatically for each design point on the Pareto front, by first running the simulation code generated from the Modelica model with the specific choice of parameters and then checking if all the requirements on critical variables are met.

\section{Case of study}

Off-shore oil and gas platforms are a proper case of study to incorporate the dynamics of the power generation system directly in the design phase, as they are typically equipped with standalone (island) power generation systems. Moreover, in off-shore applications, preventing a failure 
of the power generation system is crucial as it may cause a loss of oil and gas production and a drop of the economic revenue.

Figure 1: Simplified layout of the power generation system on the Draugen off-shore oil and gas platform. The organic Rankine cycle module is added to recover part of the thermal power released with the exhausts of turbine A.

The case of study is the power generation system installed on the Draugen oil and gas offshore platform, located $150 \mathrm{~km}$ off-shore from Kristiansund, in the Norwegian Sea. The platform, operated by A/S Norske Shell, produces natural gas, exported to Kårstø (Norway) via the Åsgard gas pipeline, and oil, which is first stored in tanks at the bottom of the sea and then exported via a shuttle tanker once every 1-2 weeks. Three Siemens SGT-500 gas turbines are installed on the platform, supplying an electrical base load of $19 \mathrm{MW}$ electric. The power demand is increased up to $25 \mathrm{MW}$ (peak load) during oil export. In order to guarantee a high reliability of the power generation system, two turbines are kept in operation at all times, each covering 50\% of the load, while the third is kept on stand-by, allowing for maintenance work. Despite the low energy conversion efficiency, this strategy ensures the necessary reserve power for peak loads, and the safe operation of the engines.

The design point specifications for the Siemens SGT-500 gas turbine are listed in Table 1 as provided by the manufacturer. The twin-spool engine employs two coaxial shafts coupling the low pressure compressor (LPC) with the low pressure turbine (LPT) and the high pressure compressor (HPC) with the high pressure turbine (HPT). The power turbine (PT) transfers mechanical power through a dedicated shaft to the electric generator (GEN).

Table 1: Design point specifications for the Siemens SGT-500 industrial twin spool gas turbine installed on the Draugen off-shore oil and gas platform.

The performance of the power generation system may be enhanced by harvesting part of the exhaust thermal power from one or more engines, by means of an ORC unit [10]. Figure 1 shows the layout of the power generation system considered in this work. Preliminary calculations suggest that incrementing the installed power by adding two or three ORC units (one for each gas turbine) is not economically feasible. In fact, the utilization factor of the whole plant decreases in 
this case, if compared to the layout given in Figure 1. Therefore, only one ORC unit is considered as the bottoming unit for gas turbine A. Due to the relatively low temperature of the gas turbine exhaust (see Table 1), its thermal energy can be transferred directly to the ORC unit through the once-through boiler (OTB), without the need of an intermediate oil loop. Thus, the working fluid is first expanded in the ORC turbine (TUR), and subsequently cooled down in the recuperator. In this way the inlet temperature in the OTB may be increased by recovering energy from the superheated vapor exiting the turbine. The ORC fluid is then condensed and pumped up to the highest pressure level through the recuperator, thus closing the cycle. Based on the analysis performed in Pierobon et al. [10], the selected ORC working fluid is cyclopentane (molecular weight 70.1 $\mathrm{kg} \mathrm{kmol}^{-1}$, critical temperature, pressure, and density $238.5{ }^{\circ} \mathrm{C}, 45.15$ bar, and $272.6 \mathrm{~kg} \mathrm{~m}^{-3}$ ). This compound is already adopted for operating ORC systems in this range of temperature see, Del Turco et al. [12]. For the steady state calculations, thermodynamic and transport properties of cyclopentane are calculated according to the model implemented in a well-known program [13]. The same thermodynamic library is linked to the dynamic modeling tool by means of a specific interface for the Modelica language [14], and a general interface to fluid property libraries, see Colonna et al. [15].

It is assumed that in the new power generation system the base-load power demand (19 MW) is shared between the combined cycle (gas turbine A and ORC) and one gas turbine, while the other engine is on stand-by. As a net power output up to $6.4 \mathrm{MW}$ can be harvested by the ORC turbogenerator [10], the load is split so that the combined cycle provides $13 \mathrm{MW}$ and the remaining $6 \mathrm{MW}$ are supplied by gas turbine B. Note that the combined cycle alone could potentially cover the entire base-load power demand with a higher efficiency; however, this option is discarded since the necessary reserve power for peak loads would not be immediately available during normal operation, as it would require the ignition of one of the gas turbines. Moreover, the proposed configuration allows to stop the combined cycle for maintenance by running gas turbine $\mathrm{B}$ and $\mathrm{C}$, each supplying $50 \%$ of the load. 


\section{System modeling}

\subsection{Preliminary ORC power plant design}

As described in Section 2.1, the design procedure starts with the calculation of the thermodynamic states of the working fluid at the inlet/outlet of each component, see Figure 1, by solving mass and energy balances, complemented by constitutive equations; the details of the non-linear system of equations can be found in Pierobon et al. [10]. At this stage, the gas turbine is modeled as a lumped thermal source, whose output constitutes the main input for the ORC turbogenerator design optimization. The characteristics assumed for the gas turbine exhaust stream are reported in Table 1. Figure 2 illustrates the $T-s$ diagrams of two ORC power unit candidates obtained via the multi-objective optimization approach described in Subsection 5.1, while the results of the thermodynamic states calculation are listed, for one such candidate designs, in Table 2.

Figure 2: Saturation curve of cyclopentane in a $T-s$ diagram (black line), showing the thermodynamic cycle state points for two exemplary ORC systems, characterized by a volume of $126 \mathrm{~m}^{3}$ (in black) and $45 \mathrm{~m}^{3}$ (in red). The gray lines represent selected isobars.

Table 2: Results of the thermodynamic states calculation for one exemplary ORC system characterized by a volume of $45 \mathrm{~m}^{3}$.

\subsubsection{Heat exchangers}

The heat exchange equipment is designed following the well-established standard procedure detailed in Coulson et al. [16]. Compared to the work carried out in Pierobon et al. [10], a new model of a once-through boiler has been developed and implemented. Moreover, as finned tubes have been foreseen in order to enhance the heat transfer process, specific correlations are utilized to evaluate the heat transfer coefficients and the pressure drops outside the tubes.

The basic design procedure of heat exchangers requires determining the surface area by evaluating, through an iterative procedure, the overall heat transfer coefficient $U_{\mathrm{o}}$ defined as

$$
\frac{1}{U_{\mathrm{o}}}=\frac{1}{h_{\mathrm{o}}}+\frac{1}{h_{\mathrm{f}, \mathrm{o}}}+\frac{d_{\mathrm{o}} \log \frac{d_{\mathrm{o}}}{d_{\mathrm{i}}}}{2 \lambda_{\mathrm{w}}}+\frac{d_{\mathrm{o}}}{d_{\mathrm{i}}} \frac{1}{h_{\mathrm{i}}}+\frac{d_{\mathrm{o}}}{d_{\mathrm{i}}} \frac{1}{h_{\mathrm{f}, \mathrm{i}}},
$$


where $h$ is the heat transfer coefficient, and $d$ is the tube diameter. The subscripts "o" and "i" stand for outer and inner with respect to the tubes, while " $\mathrm{f}$ " refers to the fouling factor. $\lambda_{\mathrm{w}}$ is the thermal conductivity of the tube-wall material.

Regarding the once-through boiler, due to the high thermal resistance of the exhaust gases flowing outside the tubes, finned tubes are selected to enhance the heat transfer coefficient $h_{\mathrm{o}}$. This is modeled by replacing the heat transfer and the fouling coefficients outside the tubes in Equation (1) with a term involving fin area and effectiveness. As the heat transfer occurs in both the singleand the two-phase region, specific equations must be adopted. In case of subcooled liquid and superheated vapor, the heat transfer coefficient inside the tubes is evaluated with the correlations proposed by Gnielinski [17]. The pressure drops related to single-phase flow are estimated using the method described in Coulson et al. [16]. The heat transfer coefficient in the two-phase region is evaluated by discretizing the tubes into 50 finite segments and then by applying the method proposed by Shah [18], adapted for horizontal tubes. The gas-side heat transfer coefficient is evaluated through the Nusselt number $N u$ using the approach proposed by the Verein Deutscher Ingenieure [19]: the correlation derived for the air-side Nusselt number in circular finned-tube heat exchangers reads

$$
N u=0.22 \operatorname{Re}^{0.6} \operatorname{Pr}^{1 / 3}\left(A / A_{\mathrm{t}}\right)^{-0.15},
$$

where $A$ is total heat transfer area and $A_{\mathrm{t}}$ is the outside surface area of the tube considering fins. The variables $\operatorname{Pr}$ and $R e$ are the Prandtl, and Reynolds numbers.

The recuperator is considered to be of the shell-and-tube type, and modeled accordingly following Coulson et al. [16]. The tubes are equipped with fins to enhance the heat transfer coefficient on the shell side, where the fluid is in the superheated vapor state. The Nusselt number on the shell side is calculated using the equation

$$
N u=0.134 \operatorname{Re}^{0.681} \operatorname{Pr}^{1 / 3}\left(\left(F_{\mathrm{p}}-F_{\mathrm{t}}\right) / F_{\mathrm{h}}\right)^{0.2}\left(F_{\mathrm{p}} / F_{\mathrm{t}}\right)^{0.1134}
$$

where $F_{\mathrm{p}}$ is the fin pitch, $F_{\mathrm{t}}$ is the fin thickness and $F_{\mathrm{h}}$ is the fin height. The pressure drops on both sides for the single-phase regions within the tubes are estimated according to Coulson et al. [16]. 
The total pressure drops occurring in the two-phase flow are estimated by dividing them into three contributions: the static one, vanishing for the proposed configuration (horizontal tubes), the kinematic one, and the one due to viscous friction. The last two terms are evaluated according to the methods proposed by Friedel [20] and Rouhani and Axelsson [21]. For the pressure drops outside the finned tubes the correlation given by Haaf [22] is adopted. The equation is valid for banks of tubes in cross flow configuration, with plain transverse fins, and it can be used for both staggered and in-line arrangement.

\subsubsection{Supersonic turbine}

The modeled expander is a turbine, which is usually the choice for ORC plants of the considered power capacity. These are usually one- or two-stage axial machines, leading to large pressure ratios across each stage; as a consequence, the flow is usually supersonic at the outlet of the first stator. The expander is therefore modeled as an equivalent choked de Laval nozzle, whose throat flow passage area is the sum of the throat areas of the nozzles constituting the first stator row.

Isentropic expansion is assumed from the inlet section, where total conditions (i.e. total pressure $p_{\mathrm{T}, 6}$ and total temperature $T_{\mathrm{T}, 6}$ ) are assumed to be known by virtue of the thermodynamic state calculation, to the throat, where sonic conditions are attained, i.e., the flow speed equals the speed of sound $c$. The corresponding equations are:

$$
\left\{\begin{array}{l}
s_{6}=s\left(p_{\mathrm{T}, 6}, T_{\mathrm{T}, 6}\right) \\
h_{\mathrm{S}, \mathrm{th}}=h_{\mathrm{T}, 6}\left(p_{\mathrm{T}, 6}, T_{\mathrm{T}, 6}\right)-\frac{1}{2} c\left(h_{\mathrm{S}, \mathrm{th}}, s_{6}\right)^{2} \\
\dot{m}=\rho_{\mathrm{S}, \mathrm{th}}\left(h_{\mathrm{S}, \mathrm{th}}, s_{6}\right) \cdot c\left(h_{\mathrm{S}, \mathrm{th}}, s_{6}\right) \cdot A_{\mathrm{th}},
\end{array}\right.
$$

where $s_{6}$ is the specific entropy at the turbine inlet, and the subscript " $\mathrm{S}$,th" indicates static conditions in the throat section. The continuity equation relates the mass flow rate through the nozzle $\dot{m}$ to the density $\rho_{\mathrm{S} \text {,th }}$ and the flow passage area $A_{\mathrm{th}}$ in the throat section. By solving system (4) for given design conditions in terms of thermodynamic state and mass flow rate at the turbine inlet, the total nozzle throat area $A_{\text {th }}$ can be evaluated. 


\subsection{Dynamic modeling}

The dynamic model of the combined cycle system is developed by using components from existing Modelica libraries. The gas turbine sub-system model is built by utilizing basic components included in the ThermoPower library [23], while the ORC system model adopts component models from the Modelica ORC library [24], with suitable adaptations regarding the heat transfer coefficients in the 1D once-through boiler model.

Figure 3: Object diagram of the gas engine sub-system.

Figure 4: Object diagram of the entire combined cycle system.

Figure 3 shows the Modelica object diagram of the GT sub-system, which has fluid connectors for air intake, fuel inlet, and exhaust gas, and one mechanical connector for the power turbine shaft. Figure 4 shows the Modelica object diagram of the entire combined cycle system. Note that, according to object-oriented modeling principles, a-causal physical connections belonging to different domains (mechanical, thermo-hydraulic, electrical) are made between the different objects; input-output connections are only used for the control systems, which are inherently causal.

\subsubsection{Gas turbine engine}

The low and high pressure compressors are described by quasi-static models, employing the maps of axial compressors provided with the commercial software developed by Kurzke [25]. The compressor maps used here are those originally from Carchedi and Wood [26]. These maps are represented by tables stating values for reduced flow, pressure ratio, isentropic efficiency and speed of revolution for the complete operating range of the component. Following the methodology proposed in Kurzke [27], the maps are scaled so that they can represent the part-load characteristic of the axial compressors of the SGT-500 gas turbine. For all the turbines, which have many stages, the Stodola equation is used to express the relation between inlet and outlet pressure, the mass flow rate and the inlet temperature in off-design operating conditions [28]. In order to predict the turbines off-design efficiency, the correlation relating the isentropic efficiency and the nondimensional flow coefficient proposed by Schobeiri [29] is utilized. The part-load performance of the electric generator is modeled using the equation proposed by Haglind and Elmegaard [30]. 
The model of the combustion chamber assumes that the mixing and the combustion processes take place inside a constant volume. The mass and the internal energy of the volume are calculated using the thermodynamic properties of the combustion products exiting the combustion chamber. Mass and energy dynamic balances are formulated, by assuming complete combustion and no heat loss to the environment (adiabatic process). The pressure drops are lumped at the outlet of the combustion chamber and are estimated by assuming a quadratic dependency with respect to the volumetric flow. The Modelica mechanical connections between the compressors, shaft inertias, turbines, and generator connector allow to compute the variation of the angular speed of the low pressure, high pressure and power turbine shaft. The values of the inertia of the rotating masses (shaft, blades, generator) and the volume of the combustion chamber are set according to data provided by the gas turbine manufacturer.

\subsubsection{ORC system}

The once-through boiler, which is one of the components of the object diagram of Figure 4, is implemented by combining basic ThermoPower modules, see Figure 5: 1D flow models for the gas side (top) and fluid side (bottom of the figure), and the 1D thermal model for the tube bundle (middle). The exchange of thermal power is modeled with so-called 1D thermal ports (in orange in the figure); the counter-current model establishes the topological correspondence between the control volumes on the tube walls, and the control volumes on the gas flow model.

Figure 5: Modelica object diagram of the once-through heat exchanger model

The tube metal wall is modeled by a 1D dynamic heat balance equation, discretized by finite volumes. The flow models contain one-dimensional dynamic mass and energy balance equations, discretized by the finite volume method, assuming a uniform pressure distribution; the relatively small friction losses are lumped in an external component model. Here, the pressure drops in offdesign conditions are estimated assuming a quadratic dependency with the volumetric flow, with the design point value set from the results of the detailed design step described in Section 4.1.1.

As the focus of the dynamic analysis is to evaluate the plant performance during critic transients, the models for the convective heat transfer are simplified in comparison to the ones adopted 
for the heat exchangers design (see Section 4.1.1). Due to their relatively small contributions, the thermal resistance in the radial direction and thermal diffusion in the axial direction are thus neglected in the dynamic models. The heat transfer coefficient between the gas and the outer pipe surface is much lower than the one between the inner pipe surface and the ORC working fluid flow. Therefore, the overall heat transfer is essentially dependent on the flue gas side only, and the working fluid temperature is always close to the inner surface temperature of the pipe.

The heat transfer coefficient at the interface between the flue gas and the metal wall, in offdesign conditions, is evaluated with the relation (see Incropera et al. [31])

$$
h=h_{\mathrm{des}}\left(\frac{\dot{m}}{\dot{m}_{\mathrm{des}}}\right)^{n},
$$

where $h$ is the heat transfer coefficient, $\dot{m}$ the mass flow rate, and the subscript "des" refers to the value at nominal operating conditions. The exponent $n$, taken equal to 0.6 , is the exponent of the Reynolds number in the heat transfer correlation. The thermal interaction between the wall and the working fluid is described by specifying a sufficiently high constant heat transfer coefficient, so that the fluid temperature is close to the wall temperature, and the overall result is dominated by the gas side heat transfer.

The model of the ORC turbine is the same as that employed in the design procedure (see Equations (4)). In this case, the throat passage area $A_{\text {th }}$ is a fixed parameter obtained from the design calculation. Hence, Equation (4) states the relation between mass flow rate and turbine inlet conditions, during off-design operation. Following Schobeiri [29], the off-design isentropic efficiency is expressed as a function of the flow coefficient $\Phi=n / \sqrt{2 \Delta h_{\text {is }}}$, with $n$ being the speed of revolution, and $\Delta h_{\text {is }}$ the isentropic enthalpy drop across the expansion.

The recuperator is modeled by the counter-current connection of 1D ThermoPower modules, much as the once-through boiler, see Figure 5. The heat transfer on the vapor side dominates, therefore the overall heat transfer coefficient is taken equal to that at the interface between the working fluid and the metal wall. Both the overall heat transfer in off-design conditions, and the pressure drops are modeled as already detailed for the once-through boiler.

The condenser is trivially modeled as a fixed pressure component. This is justified considering the large availability of cooling sea-water, which allows the cooling circuit to be controlled in such 
a way that the condenser pressure is nearly constant. For simplicity, the condensate is assumed to leave the component in saturated conditions (no subcooling) with no pressure losses.

The pump model is based on a head-volume flow curve derived by fitting the data of an existing centrifugal pump designed for similar volumetric flows and heads. The curve is given as a function of $\phi=\dot{m} / \rho \cdot \rho_{\mathrm{des}} / \dot{m}_{\mathrm{des}}$ and can be expressed as

$$
H=H_{\mathrm{des}} \cdot\left(b_{1}+b_{2} e^{\phi}\right) \cdot\left(\frac{n}{n_{\mathrm{des}}}\right)^{2},
$$

where $H$ is the head, $b_{1}=2.462$, and $b_{2}=-0.538$. The exponential functional form is selected in order to result in a monotonic relation, thus increasing the model robustness compared to typically adopted polynomial expressions. The isentropic efficiency of the pump is expressed as a function of the coefficient $F=\phi \cdot n_{\text {des }} / n$ using the methodology proposed by Veres [32].

The off-design electric efficiency of the ORC generator is calculated as for the case of the gas turbine generator, while the electro-mechanic efficiency of the pump motor is evaluated by assuming a quadratic dependency on the ratio between the actual load and its nominal value.

\subsubsection{Control systems}

As explained in Section 3, the system under consideration operates off-grid. The alternating current (AC) grid-system of the off-shore platform is powered by the two synchronous generators connected to the gas and ORC turbines, which can be assumed to rotate at the same speed, as the electrical connections are very short. The gas turbine features the fastest load response, so it is used to control the network frequency (or, equivalently, the shaft rotational speed). As the low pressure and high pressure compressor are not equipped with variable inlet guide vanes, the load can only be controlled by opening or closing the fuel valve. The feedback controller included in the gas turbine sub-system (see Figure 3) replicates the functional model provided by the gas turbine manufacturer, including the controller transfer function, and a simplified model of the fuelsystem dynamic response, also given as a transfer function. Note that this controller is embedded in the GT unit and its parameters cannot be changed by the end-user, so the controller parameters are taken as they are in the context of this study.

The goal of the ORC control system is to target the maximum possible heat recovery from the GT exhaust, while ensuring that no acid condensation takes place, which might be particularly 
dangerous, as heavy fuels can be fed to the turbine combustor. This goal is attained by using the feed pump speed to control the temperature of the exhaust gases exiting the OTB at the design point value, which is as low as possible, yet high enough to avoid condensation. During stationary operation, the design of the heat exchanger is such that the highest temperature of the organic fluid, at the turbine inlet, is lower by a safety margin with respect to the thermal decomposition temperature of the working fluid. In addition, the control system must ensure that this temperature does not exceed the safety limit anywhere in the high-temperature part of the ORC power plant during system transients.

The most critical operational transient from this point of view is the trip of gas turbine B: when this happens, the network frequency drops, so the GT controller reacts by opening the fuel valve to regain the set-point frequency. Consequently, the GT exhaust flow rate and temperature increase, leading to an increase of the OTB exhaust gases temperature, which is then counteracted by the ORC controller by increasing the feed flow to the OTB and thus, eventually, also the share of the load generated by the ORC system.

Preliminary simulations carried out with different designs of the system showed that, as expected, the dynamic response of the ORC system is much slower than the response of the GT system, even for aggressive designs of the temperature controller. This leads to significant and potentially unacceptable overshoot of the pump speed during the transient. This means that the peak value of the turbine inlet temperature (which is one of the critical variables of the process) is almost insensitive to the tuning of the ORC system controller. Such peak is quickly reached due to the fast response of the GT compared to the ORC system. In particular, the response time of the ORC power system is comparatively long since the flow rate through the turbine, and thus the generated power, change very slowly with the OTB pressure. This means that the contribution of the ORC controller to the limitation of the frequency undershoot is marginal.

Based on these considerations, the ORC Proportional-Integral (PI) controller was tuned in order to obtain the minimum possible settling time of the controlled variable, while avoiding the overshoot of the pump speed during the trip response transient and obtaining well-damped responses for all involved variables. The simulations showed that this is possible by setting the proportional gain to a value that is proportional to the heat exchanger volume, thus accounting 
for the process gain variability with the design parameters, while keeping the integral time at a suitable constant value.

\subsection{Validation}

The shell and tube heat exchanger design model, described in Section 4.1.1, was validated using an example outlined in Coulson et al. [16]. The differences between the simulation results and the data reported in the reference are within $1 \%$ in terms of both overall heat transfer coefficient and pressure drops. For the once-through boiler it is verified that the heat transfer coefficients and the pressure drops related to both singe- and two-phase flow are within the range of values specified in Dumont and Heyen [33].

Figure 6: Dynamic validation results, normalized frequency vs time. Comparison between the reference model provided by the gas turbine manufacturer and the model developed in the present work.

The off-design, steady-state simulation results of the gas turbine model presented in Section 4.2.1 were compared to the partial load characteristics given by the gas turbine manufacturer in the 10\%-100\% range. Exhaust gas mass flow rate and temperature, fuel mass flow rate, and pressure in the combustion chamber were checked. The quantity showing the larger mismatch is the fuel mass flow: the relative error is about $3 \%$ for loads larger than $60 \%$, and increases up to about $15 \%$ if the load decreases down to $10 \%$.

The dynamic model of the gas turbine was validated by comparison with simulation results of the reference model provided by the gas turbine manufacturer, which is based on proprietary experimental data. The validation scenario assumes that the three GT units initially share a total load of $24 \mathrm{MW}$, delivering $8 \mathrm{MW}$ each. At some point in time, one unit trips, so the other two ramp up their load in order to match the total power demand, with a transient reduction of the network frequency. The result of the simulations are compared in Figure 6, which shows the normalized network frequency and the load of unit B. At time $t=50$ seconds, one of the gas turbines trips; subsequently, the reference model predicts a minimum normalized frequency drop of 0.0206 and a rise time of $5.5 \mathrm{~s}$, while the model presented in this paper gives a normalized frequency drop of 0.0202 and a rise time of $6.0 \mathrm{~s}$. Based on this results, it is possible to conclude that the gas turbine 
dynamic model developed in the present work is able to reproduce both the steady-state and the dynamics of the gas turbine with reasonable accuracy, over the entire range of loads encountered during real operation.

The model of the ORC system is composed of software objects taken from a library that was developed in order to model a $150 \mathrm{~kW}$ ORC system using toluene as the working fluid, and successfully validated for transient operation against experimental data as discussed in Casella et al. [24]. The developed models are therefore deemed reliable, considering the similarity of the application at hand with the one presented in the cited reference. Furthermore, it has been verified that the on-design and off-design steady-state operating points predicted by the ORC system model are consistent with those computed by the design tool described in Section 4.1.

\subsection{The DYNDES tool}

The DYNDES computer tool couples steady state and the dynamic software models in order to provide an integrated program for the optimal design of power generation systems, including dynamic criteria. The two computer programs are interfaced by means of shared files and command scripts. More in detail, the results of the multi-objective design optimization is saved in an appropriate file, then the dynamic simulation program is run in command-line mode to: i) extract information from the design results file (e.g. the optimal design data relative to the geometry of the once-through boiler), ii) convert such data into parameters and inputs for the dynamic models, iii) run the simulations, and iv) save quantities of interest for further post-processing. Figure 7 shows the flowchart of the DYNDES tool.

Figure 7: Architecture of the DYNDES design tool. The results of the multi-objective design optimization are utilized as inputs for the dynamic simulations of the power generation system. The software integrates the steady state and the dynamic model via a scripting command.

Starting from the same computing environment that is used for the steady-state model, the available multi-objective optimizer runs by first acquiring the array of the parameters and of the upper and lower bounds for the vector of the optimization variables $\bar{X}$, which in the case at hand reads

$$
\bar{X}=\left[p_{6}, \Delta T_{\mathrm{r}}, \Delta T_{\mathrm{OTB}}, T_{11}, d_{\mathrm{i}, \mathrm{OTB}}, t h_{\mathrm{OTB}}, l_{\mathrm{OTB}}, u_{\mathrm{exh}}, d_{\mathrm{i}, \mathrm{r}}, t h_{\mathrm{r}}, l_{\mathrm{r}}, p t, l_{\mathrm{b}}\right]
$$


where $p_{6}$ is the turbine inlet pressure, $\Delta T_{\mathrm{r}}=T_{8}-T_{2}$ the minimum temperature difference in the recuperator, and $\Delta T_{\mathrm{OTB}}$ the temperature difference between the two streams in the once-through boiler, at the location where the ORC fluid is in saturated liquid condition. Note that this does not necessarily correspond to the so-called pinch-point of the heat exchanger, since the minimum temperature difference between the two streams in the OTB might also be located at its inlet. The variables $u_{\mathrm{exh}}, d_{\mathrm{i}, \text { ОтВ }}, t h_{\mathrm{OTB}}$ and $l_{\text {Отв }}$ are the velocity of the exhaust gases, the inner diameter, the thickness and the length of the tubes of the once-through boiler. The unknowns $p t, l_{\mathrm{b}}, d_{\mathrm{i}, \mathrm{r}}, t h_{\mathrm{r}}$ and $l_{\mathrm{r}}$ refer to the tube pitch, the baffle spacing (given as a percentage of the shell diameter), the diameter, the thickness and the length of the tubes of the recuperator.

The array of the objective functions $\bar{J}$ assumed in the present work is

$$
\bar{J}=\left[-P_{\text {net,ORC }}, V_{\text {OTB }}+V_{\mathrm{r}}\right],
$$

where $P_{\text {net,ORC }}$ is the net power output of the ORC power unit, and the second metric accounts for total ORC module volume which is determined by the more bulky components, i.e., the oncethrough boiler and the recuperator. The first term is selected in order to maximize the power output of the combined cycle plant while the latter term is added to the objective function since compactness represents a crucial design requirement in the considered application. The integration of dynamic simulations into the the automated design procedure allows to discard unfeasible designs. Since the dynamics of the condenser can be neglected for the reasons explained in Section 4.2.2, the volume of the condenser is not included in the second term of the objective function, see Equation 8.

The multi-objective optimization [34] uses a controlled elitist genetic algorithm (GA) to search for solutions which minimize simultaneously the two objective functions. Compared to gradientbased methods, a GA is less prone to converge to local minima of the problem. This typically comes at the cost of an increased computational cost, due to the large number of evaluations of the objective functions [34]. The GA parameters are specified as follows: population size equal to 200 , generation size equal to 100 , crossover fraction equal to 0.8 , and migration fraction equal to 0.2. These numerical values are selected in order to ensure the repeatability of the solution when different simulations are performed, and are selected after Deb [34]. 
Table 3 lists the upper and lower bounds utilized for the optimization variables, according to the limits reported by Coulson et al. [16]. As the SGT-500 engine can operate on a wide range of both liquid and gas fuels, the limit temperature of the flue gas at the outlet of the OTB is set to $140{ }^{\circ} \mathrm{C}$, in order to prevent the condensation of corrosive compounds. Supercritical cycle configurations are not considered here because such systems are still in the development phase, therefore the upper bound for the turbine inlet pressure is set equal to $90 \%$ of the critical pressure of cyclopentane.

Table 4 lists the parameters which are kept constant during the multi-objective optimization. The fin profile and the configuration of the once-through boiler and of the recuperator are retrieved from Dumont and Heyen [33] and Coulson et al. [16]. The condensing pressure of the working fluid is fixed to $1 \mathrm{bar}$, corresponding to a temperature of $50{ }^{\circ} \mathrm{C}$, in order to avoid inward air leakage into the condenser.

Table 3: Lower and upper bound for the variables of the multi-objective optimization.

Table 4: Parameters assumed for the multi-objective optimization.

Referring to Figure 7, the calculation loop regarding the ORC module determines the thermodynamic states at the inlet and at the outlet of each component, as detailed in Pierobon et al. [10]. The pressure drops in the heat exchangers are initially set to zero. At this point the design procedure of the once-through boiler and of the recuperator (see Section 4.1.1) is started, obtaining as outputs both the pressure drops and the design parameters of the components, which are then stored. The model of the ORC system is thus run again, but in this case the pressure losses in the OTB and in the recuperator are included in the computation. The results are then checked with respect to the second principle of Thermodynamics. It is also verified that the velocity in the tubes and on the shell side of the recuperator lies within the ranges specified in Coulson et al. [16]. The process is repeated until the average change in the spread of the Pareto front is lower than the specified tolerance, which is assumed here equal to $10^{-3}$. When the multi-objective optimization terminates, the inputs of the dynamic models are stored in a file that is then used by the dynamic simulator as previously explained. 
The dynamic models are parametrized using the data for the heat exchangers and the turbine corresponding to the optimal ORC modules, as determined by the multi-objective optimization procedure. These models are then used to predict the dynamics of the complete system in a predefined transient scenario. Note that the number of dynamic simulations to be performed is equal to the number of points of the Pareto front.

The dynamic test, conceived to assess the dynamics of the complete system, consists in the simulation of the failure of a gas turbine unit. This has been defined according to the specifications of the platform owner, and represents the worst possible scenario the power system can possibly undergo without compromising the platform functionality. The same dynamic test is thus applied to all the design candidates previously defined.

It is assumed that the combined cycle (gas turbine A and ORC) and the gas turbine B are providing the normal load (13 and $6 \mathrm{MW}$ each) while at time $\mathrm{t}_{0}$ gas turbine $\mathrm{B}$ trips. Hence, the combined cycle undergoes a load increment of $1.2 \mathrm{MW} / \mathrm{s}$ (e.g. $6 \mathrm{MW}$ in $5 \mathrm{~s}$, see Figures 8(b) and 10(a)) and must take over the entire power demand, until gas turbine $\mathrm{C}$ is ignited. The process ends by storing the desired outputs of the dynamic analysis (e.g., the maximum undershoot of the electrical network frequency) for each choice of system design. Finally, post-processing is performed within the software environment for scientific computing.

\section{Results and discussion}

\subsection{Multi-objective design optimization}

Table 5 lists the results of the multi-objective optimization procedure applied to the test case. The arithmetic mean average (AMA), the percentage relative standard deviation (RSD), and the minimum and maximum values of the optimized variables are reported. A low RSD means that the variable does not change significantly with the optimal configurations of the ORC unit. The pinch point, the tube diameter and the tube pitch of the recuperator present the lowest RSDs. As a practical implication, Table 5 provides the designer with the optimal geometry of the heat transfer equipment; the closest available standardized values can then be selected for the design of the actual equipment. 
Figure 8(a) shows the two-dimensional Pareto front which relates the net power output of the ORC module with the sum of the volumes of the once-through boiler and of the recuperator. The Pareto front is formed by 70 optimal solutions, ranging from a net ORC power of $3.9 \mathrm{MW}$ up to 5.8 MW. The trend of the volume vs. the net power output is approximately hyperbolic. The total net power output and the thermal efficiency of the combined cycle unit range from $20.4 \mathrm{MW}$ to 22.3 MW and from $38.7 \%$ to $42.2 \%$. Due to space constraints on the Draugen platform, design points with a volume higher than $100 \mathrm{~m}^{3}$ are discarded from the Pareto front (triangular dots in Figure 8(a)).

Table 5: Results of the multi-objective optimization. Maximum, minimum, arithmetic mean average, and relative standard deviation of the optimized variables. The values are relative to the 70 points of the Pareto front.

\subsection{Assessment of dynamic performance}

As far as the results of the analysis of the system dynamics are concerned, Figure 8(b) illustrates the transient response of the system for two points of the Pareto front (i.e., those corresponding to the designs with the largest and the smallest volume). The influence of the ORC power module design on the network frequency transient is clearly visible: the lower the volume, the larger the undershoot and the overshooting of the frequency. On the contrary, large values of the volume limit the frequency drop, by increasing the thermal inertia of the system.

Figure 9(a) relates the volume to the minimum frequency reached during the transient, for each point of the Pareto front. The curve presents a highly non-linear trend, with the magnitude of the frequency variations increasing more sharply for decreasing volume. According to the standards for power quality adopted by the platform owner, the frequency undershoot must not exceed $4 \%$ of the nominal value. Thus, as results from the dynamic analysis, ORC power modules characterized by overall volume $V_{O R C}$ lower than $50 \mathrm{~m}^{3}$ violate this constraint. These designs are therefore identified as unfeasible, and marked with the hollow square ( $\square$ ) symbol in Figures 8(a) and 9(a). Figure 9(b) reports the rise time as a function of volume. The rise time is defined here as the time required for the frequency to return back to $99 \%$ of the value at steady state. The trend of the curve is also non-linear with a minimum of approximately $14 \mathrm{~s}$ at $65 \mathrm{~m}^{3}$. 
(a)

(b)

Figure 8: 8(a) multi-objective optimization results, Pareto front showing the relation between the objective functions, e.g. the ORC system net power and the volume of the heat transfer equipment $V_{\mathrm{ORC}}$. The designs identified by the $\square$ symbol are discarded due to the unacceptable frequency undershoot, while those marked with $\Delta$ due to volume limitations. The other designs (filled circles) are deemed acceptable. 8(b) results of the dynamic test, the grey line represents the corresponding load variation. Normalized frequency and combined cycle load vs time for the two designs characterized by the maximum and minimum values of $V_{\mathrm{ORC}}$.

(a) (b)

Figure 9: Results of the dynamic test. 9(a) frequency undershoot vs volume $V_{\mathrm{ORC}}$, all the points of the Pareto front are reported. The designs identified by the $\square$ symbol are discarded due to the unacceptable frequency undershoot (> 4\%). 9(b) rise time vs $V_{\mathrm{ORC}}$, all the points of the Pareto front are reported.

(a) (b)

Figure 10: Results of the dynamic test, the grey line represents the corresponding load variation. 10(a) turbine inlet temperature $T_{6}$, and exhaust gases temperature at the once-through boiler inlet $T_{10}$ vs time for three selected designs corresponding to points of the Pareto front (the two designs characterized by the maximum and minimum volume of the heat exchanging equipment $V_{\mathrm{ORC}}$, together with an intermediate value). 10(b) maximum turbine inlet temperature vs $V_{\mathrm{ORC}}$, all the points of the Pareto front are reported. 
Figure 10(a) shows the time evolution of the temperature at the inlet of the ORC turbine $T_{6}$, together with that of the exhaust gases exiting the gas turbine $T_{10}$ for three points of the Pareto front. As the load of the gas turbine undergoes a sharp variation, the temperature and the mass flow of the exhaust gases entering the OTB rise. As anticipated in Section 4.2.3, the dynamics of $T_{6}$ is much slower than that of $T_{10}$. The two major contributions to the delay are the inertia of the metal walls and of the working fluid in liquid phase contained in the heat exchangers. Note that, while the mass of the exhaust gases is negligible, that of the liquid cyclopentane contained in the OTB and in the recuperator is approximately 15 times larger than its mass in the vapor phase.

The peak of $T_{6}$ is reported as a function of volume in Figure 10(b). This value is of paramount importance, being closely related to the maximum temperature reached by the ORC working fluid. This is eventually encountered in the fluid layer close to the metal wall in the boiler (OTB) but, as a consequence of the approximations introduced in Section 4.2.2, the accurate evaluation of its value is presently beyond the capability of the developed models. As a rough estimation, design point calculations using the methodology outlined in Section 4.1.1 indicate that the wall temperature of cyclopentane in the hotter part of the OTB is expected to be $10-30{ }^{\circ} \mathrm{C}$ higher than the corresponding bulk value. As the thermal stability of the working fluid is a major concern in the design of ORC systems, the minimum risk of decomposition should be ensured. In a recent work, Ginosar et al. [35] identified $300{ }^{\circ} \mathrm{C}$ as the upper temperature limit for safe operations of an ORC system working with cyclopentane. Therefore, a maximum temperature at the turbine inlet of $270{ }^{\circ} \mathrm{C}$ can be accepted, which is also in agreement with other published information, see e.g. Del Turco et al. [12].

The dynamic analysis allows to identify a clear minimum for $T_{6}$ which, for the considered case, lies at around $250{ }^{\circ} \mathrm{C}$, with a volume of $65 \mathrm{~m}^{3}$. Values close to $265^{\circ} \mathrm{C}$ are achieved for both smaller and larger volumes. Even though the estimated safety limit is not exceeded, the designs characterized by values of volume ranging from 60 to $80 \mathrm{~m}^{3}$ may be deemed preferable in the light of the present analysis, as they are located in vicinity of the minimum $T_{6}$. 


\section{Conclusions}

The design of innovative energy conversion systems conceived for flexible operation needs to take into account dynamic requirements on critical transient scenarios as early as possible in the design cycle, in order to avoid costly design changes in later phases, or sub-optimal system performance. The methodology and tools presented in this paper are a first methodological attempt in this direction.

The design tool DYNDES presented here demonstrates the potential of this preliminary automated design method, if the main design objectives are aspects such as system performance, compactness and flexibility. The software utilizes the multi-objective optimization approach to search for optimal designs with potentially conflicting objectives, which the user can select based on the specific requirements of the system under investigation. As the routine optimizes the geometry of the heat transfer equipment, such a procedure bridges the gap between the mere optimization of the thermodynamic cycle and the preliminary design of system components that constitutes the first step towards the realization of power systems. The system response during transients becomes one of the crucial design criteria, leading to the exclusion from the optimal solutions of several designs which do not satisfy dynamic requirements, e.g., the tolerance on network frequency variations.

The proposed methodology has been applied to the case study of an ORC-based combined cycle power plant for an off-grid oil platform. The test cases demonstrates how dynamic analysis enables to exclude those system configurations which, although potentially more efficient or compact, may lead to unacceptable frequency fluctuations, or increase the risk of decomposition of the working fluid.

The proposed methodology and tools are readily applicable to other systems combining gas turbines and ORC power modules, but can also be extended to cover other cases of advanced energy conversion systems with demanding dynamic requirements, such as power generation in grids with high renewable energy penetration, off-grid energy conversion systems, heat recovery in automotive engines, solar thermal plants, etc. 


\section{Acknowledgments}

The funding from the Norwegian Research Council through Petromaks with project number 203404/E30 and from the Dutch Technology Foundation STW, Applied Science Division of NWO and the Technology Program of the Ministry of Economic Affairs, grant \# 11143 are acknowledged. We also acknowledge the kind support from Siemens Industrial Turbomachinery AB, Finspång, Sweden for providing the dynamic model of the SGT-500 gas turbines and the necessary technical documentation.

\section{References}

[1] Lise, W., van der Laan, J., Nieuwenhout, F., Rademaekers, K.. Assessment of the required share for a stable EU electricity supply until 2050. Energy Policy 2013;59(0):904 - 913.

[2] Bancalari, E., Chan, P.. Adaptation of the SGT6-6000G to a dynamic power generation market. In: Proceedings of the 2005 Power-Gen International Conference. Las Vegas, Nevada; 2005, p. 6-8.

[3] Keatley, P., Shibli, A., Hewitt, N.. Estimating power plant start costs in cyclic operation. Applied Energy 2013;111:550-557.

[4] Lin, J., Sun, Y., Song, Y., Gao, W., Sorensen, P.. Wind power fluctuation smoothing controller based on risk assessment of grid frequency deviation in an isolated system. IEEE Transactions on Sustainable Energy 2013;4(2):379-392.

[5] He, W., Jacobsen, G., Anderson, T., Olsen, F., Hanson, T., Korpoas, M., et al. The potential of integrating wind power with offshore oil and gas platforms. Wind Engineering 2010;34(2):125-138.

[6] Garcia, H., Mohanty, A., Lin, W.C., Cherry, R.. Dynamic analysis of hybrid energy systems under flexible operation and variable renewable generation - Part I: Dynamic performance analysis. Energy 2013;52:1-16.

[7] Zhu, Y., Tomsovic, K... Development of models for analyzing the load-following performance of microturbines and fuel cells. Electric Power Systems Research 2002;62:1-11.

[8] Alobaid, F., Postler, R., Ströhle, J., Epple, B., Kim, H.G.. Modeling and investigation start-up procedures of a combined cycle power plant. Applied Energy 2008;85(12):1173 - 1189.

[9] Lopez-Negrete, R., D’Amato, F.J., Biegler, L.T., Kumar, A.. Fast nonlinear model predictive control: Formulation and industrial process applications. Computers \& Chemical Engineering 2013;51(0):55 - 64.

[10] Pierobon, L., Nguyen, T.V., Larsen, U., Haglind, F., Elmegaard, B.. Multi-objective optimization of organic Rankine cycles for waste heat recovery: Application in an offshore platform. Energy 2013;58(0):538 - 549.

[11] Fritzson, P.. Principles of Object-Oriented Modeling and Simulation with Modelica 2.1. Piscataway, United States of America: John Wiley \& Sons, Inc.; 2003. ISBN: 9780470937617. 
[12] Del Turco, P., Asti, A., Del Greco, A., Bacci, A., Landi, G., Seghi, G.. The ORegen waste heat recovery cycle: Reducing the $\mathrm{CO}_{2}$ footprint by means of overall cycle efficiency improvement. In: Proceedings of ASME Turbo Expo 2011. Vancouver, Canada; 2011, p. 547-556.

[13] Lemmon, E., McLinden, M., Huber, M.. Refprop: Reference fluid thermodynamic and transport properties. NIST standard reference database 2007;23(8.0).

[14] Casella, F., Richter, C.C.. ExternalMedia: a library for easy re-use of external fluid property code in Modelica. In: Bachmann, B., editor. Proceedings 6th International Modelica Conference. Bielefeld, Germany: Modelica Association; 2008, p. 157-161.

[15] Colonna, P., van der Stelt, T.P., Guardone, A.. FluidProp (Version 3.0): A program for the estimation of thermophysical properties of fluids. 2012. A program since 2004.

[16] Coulson, J., Richardson, J., Backhurst, J.. Coulson and Richardson's Chemical Engineering. Chemical engineering; Oxford, Great Britain: Butterworth-Heinemann; 1999. ISBN: 9780750644440.

[17] Gnielinski, V.. On heat transfer in tubes. International Journal of Heat and Mass Transfer 2013;63(0):134 140.

[18] Shah, M.. Chart correlation for saturated boiling heat transfer: equations and further study. ASHRAE Transaction 1982;88(1):185-196.

[19] Verein Deutscher Ingenieure, . VDI-Wärmeatlas: Berechnungsblätter für den Wärmeübergang. Berlin, Germany: Springer-Verlag; 1953. ISBN: 9783540412014.

[20] Friedel, L.. Pressure drop during gas/vapor-liquid flow in pipes. International Chemical Engineering $1980 ; 20(3): 352-367$.

[21] Rouhani, S.Z., Axelsson, E.. Calculation of void volume fraction in the subcooled and quality boiling regions. International Journal of Heat and Mass Transfer 1970;13(2):383-393.

[22] Haaf, S.. Wärmeübertragung in luftkühlern. In: Wärmeaustauscher. Berlin, Germany: Springer Verlag; 1988, p. 435-491. ISBN: 9783540154778.

[23] Casella, F., Leva, A.. Object-oriented modelling \& simulation of power plants with modelica. In: Proceedings 44th IEEE Conference on Decision and Control and European Control Conference 2005. Seville, Spain: IEEE, EUCA; 2005, p. 7597-7602.

[24] Casella, F., Mathijssen, T., Colonna, P., van Buijtenen, J.. Dynamic modeling of ORC power systems. Journal of Engineering for Gas Turbines and Power 2012;135:1-12.

[25] Kurzke, J.. Component map collection 2, Compressor and turbine maps for gas turbine performance computer programs. Germany; 2004, www.gasturb.de/. [accessed: 19/09/2013]; 2004.

[26] Carchedi, F., Wood, G.R.. Design and development of a 12:1 pressure ratio compressor for the Ruston 6-MW gas turbine. Journal for Engineering for Power 1982;104:823 - 831.

[27] Kurzke, J.. How to create a performance model of a gas turbine from a limited amount of information. In: 
Proceedings of ASME Turbo Expo 2005. Reno-Tahoe, Nevada; 2005, p. 145-153.

[28] Stodola, A.. Dampf- und Gasturbinen: Mit einem Anhang über die Aussichten der Wärmekraftmaschinen. Berlin, Germany: Springer Berlin; 1922. ISBN: 7352997563.

[29] Schobeiri, M.. Turbomachinery flow physics and dynamic performance. Berlin, Germany: Springer Berlin; 2005. ISBN: 9783540223689.

[30] Haglind, F., Elmegaard, B.. Methodologies for predicting the part-load performance of aero-derivative gas turbines. Energy 2009;34(10):1484 - 1492.

[31] Incropera, F.P., DeWitt, D.P., Bergman, T.L., Lavine, A.S.. Fundamentals of Heat and Mass Transfer. 6 ed.; Jefferson City, United States of America: John Wiley \& Sons, Inc.; 2007. ISBN: 9780470501979.

[32] Veres, J.P.. Centrifugal and axial pump design and off-design performance prediction. Tech. Rep.; NASA; Sunnyvale, United States of America; 1994. Technical Memorandum 106745.

[33] Dumont, M.N., Heyen, G.. Mathematical modelling and design of an advanced once-through heat recovery steam generator. Computers \& Chemical Engineering 2004;28(5):651 - 660.

[34] Deb, K.. Multi-objective optimization using evolutionary algorithms. West Sussex, Great Britain: John Wiley \& Sons, Inc.; 2001. ISBN: 9780470743614.

[35] Ginosar, D.M., Petkovic, L.M., Guillen, D.P.. Thermal stability of cyclopentane as an organic Rankine cycle working fluid. Energy \& Fuels 2011;25(9):4138-4144. 

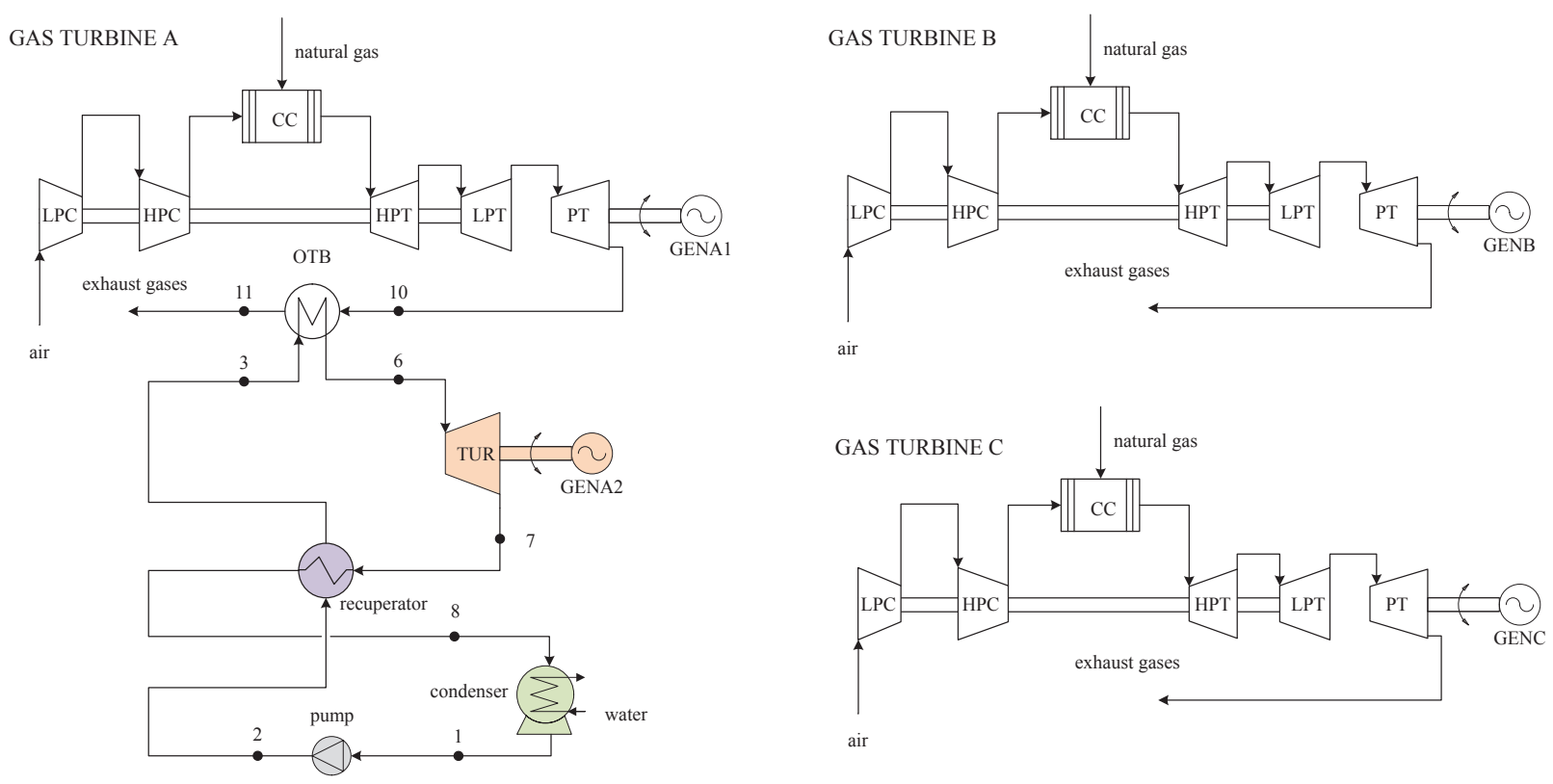

Figure 1: Simplified layout of the power generation system on the Draugen off-shore oil and gas platform. The organic Rankine cycle module is added to recover part of the thermal power released with the exhausts of turbine A. 


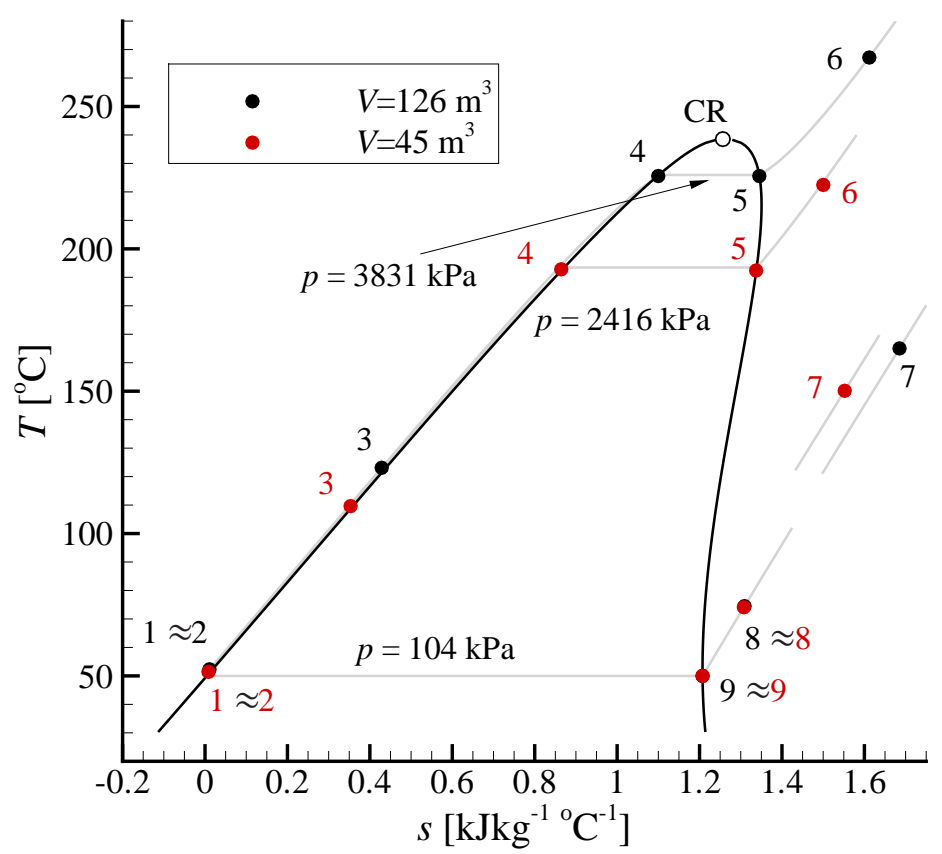

Figure 2: Saturation curve of cyclopentane in a $T-s$ diagram (black line), showing the thermodynamic cycle state points for two exemplary ORC systems, characterized by a volume of $126 \mathrm{~m}^{3}$ (in black) and $45 \mathrm{~m}^{3}$ (in red). The gray lines represent selected isobars. 


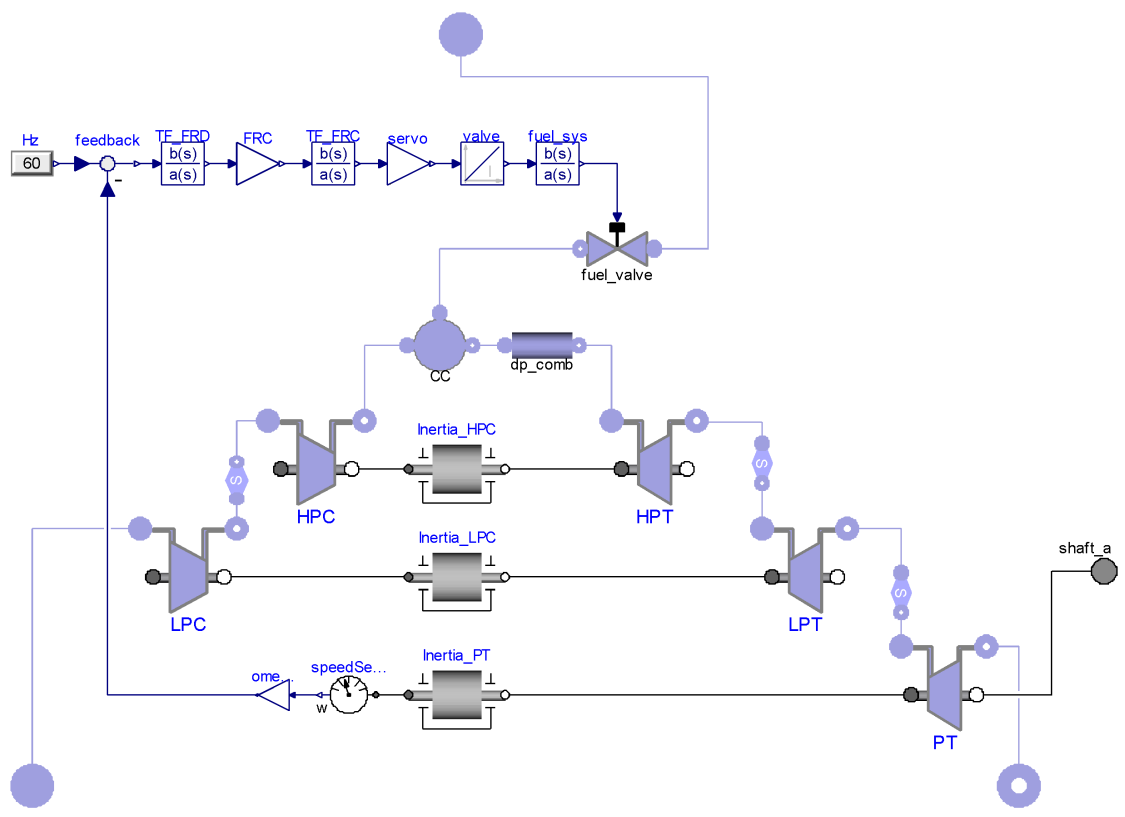

Figure 3: Object diagram of the gas engine sub-system. 


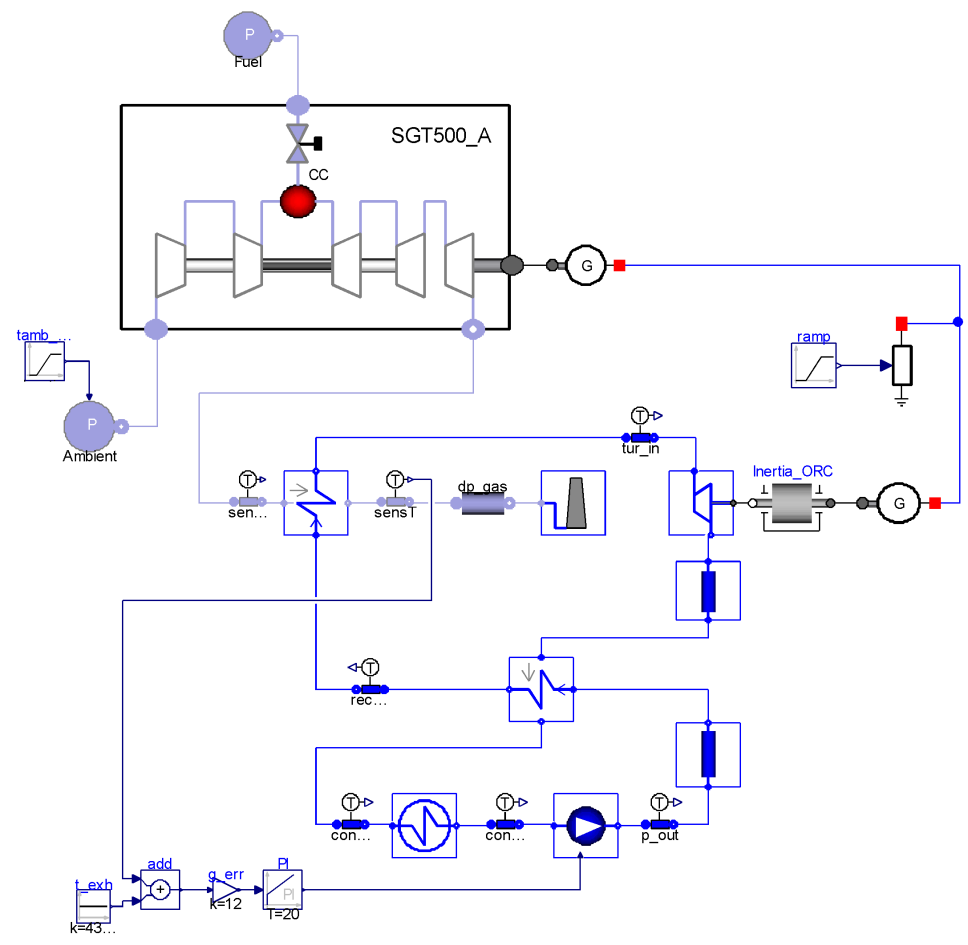

Figure 4: Object diagram of the entire combined cycle system. 


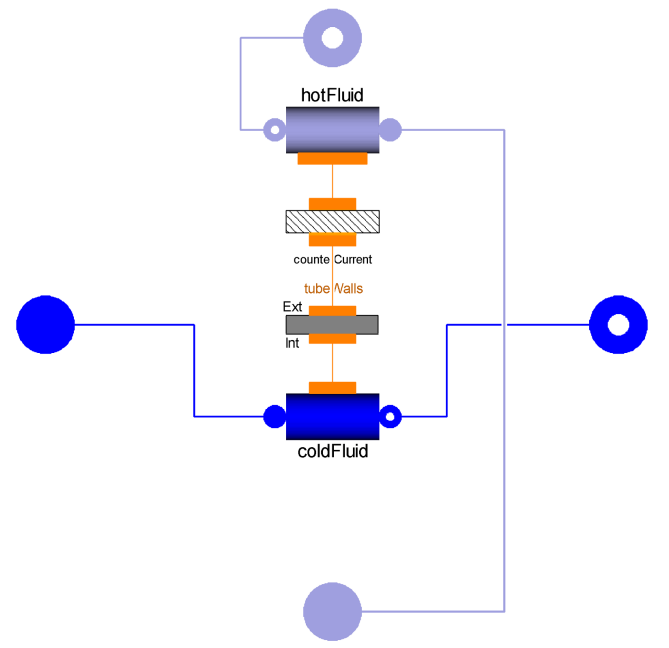

Figure 5: Modelica object diagram of the once-through heat exchanger model 


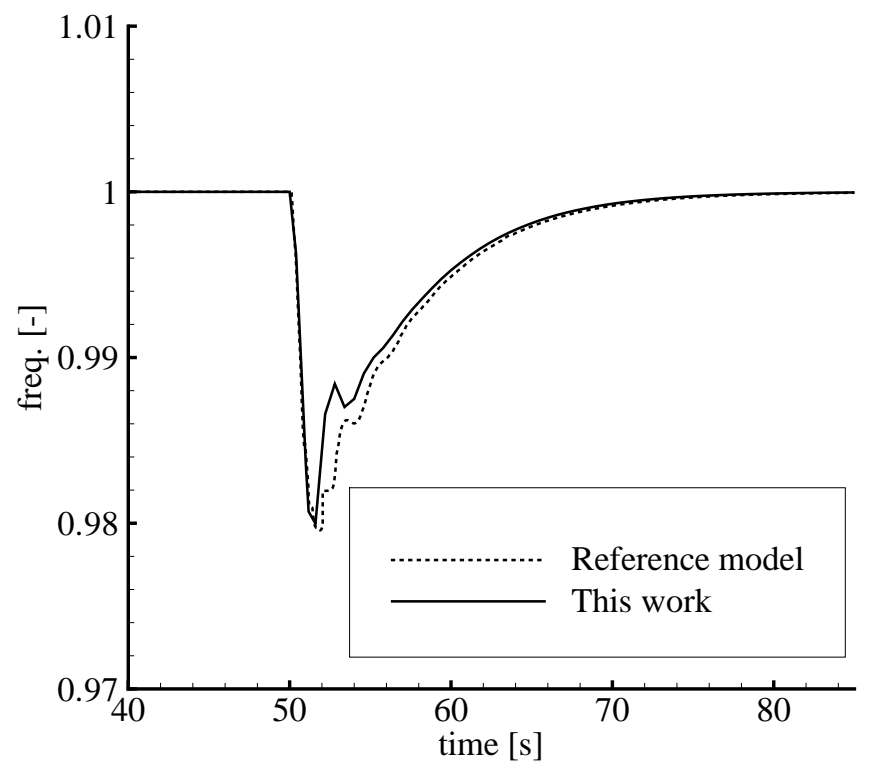

Figure 6: Dynamic validation results, normalized frequency vs time. Comparison between the reference model provided by the gas turbine manufacturer and the model developed in the present work. 


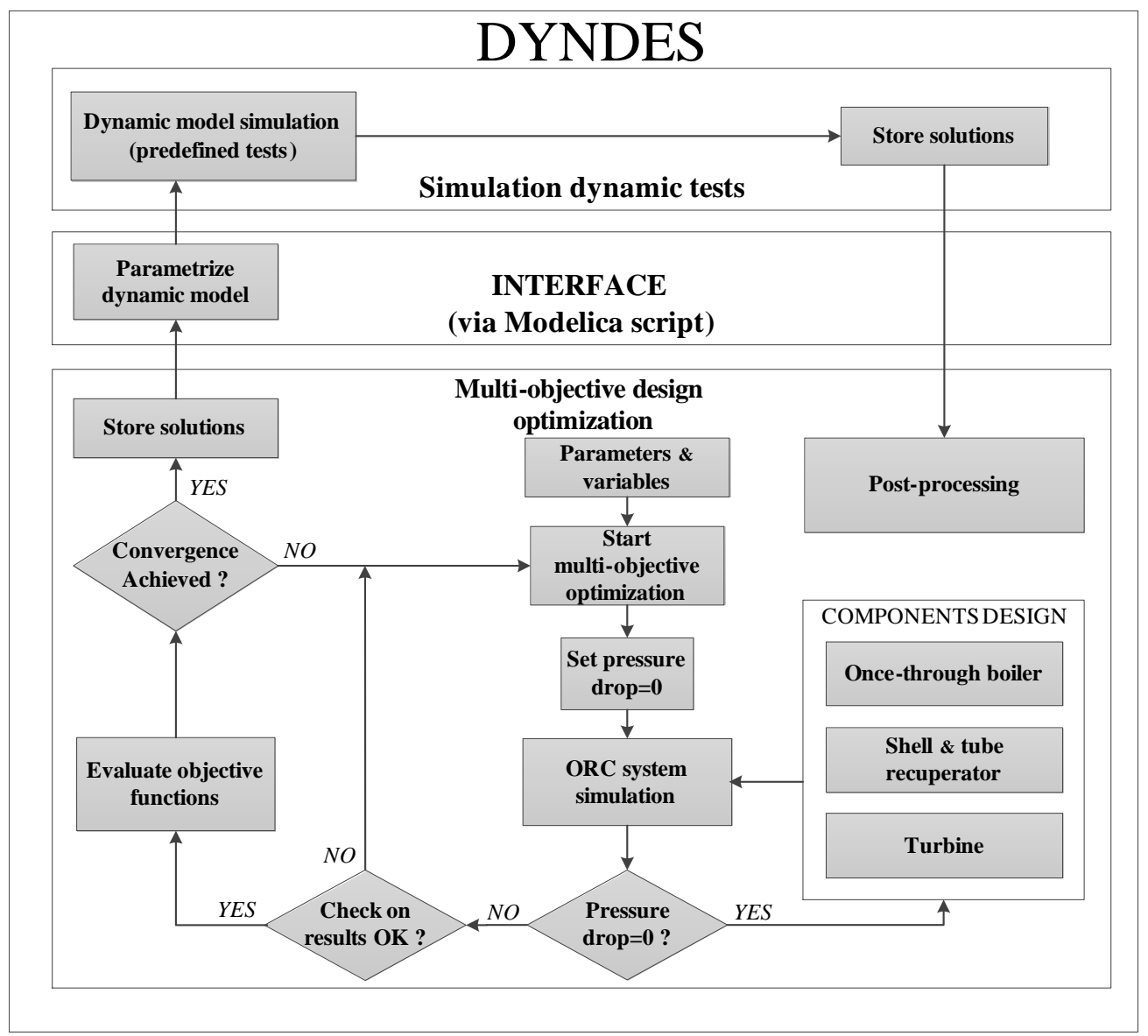

Figure 7: Architecture of the DYNDES design tool. The results of the multi-objective design optimization are utilized as inputs for the dynamic simulations of the power generation system. The software integrates the steady state and the dynamic model via a scripting command. 


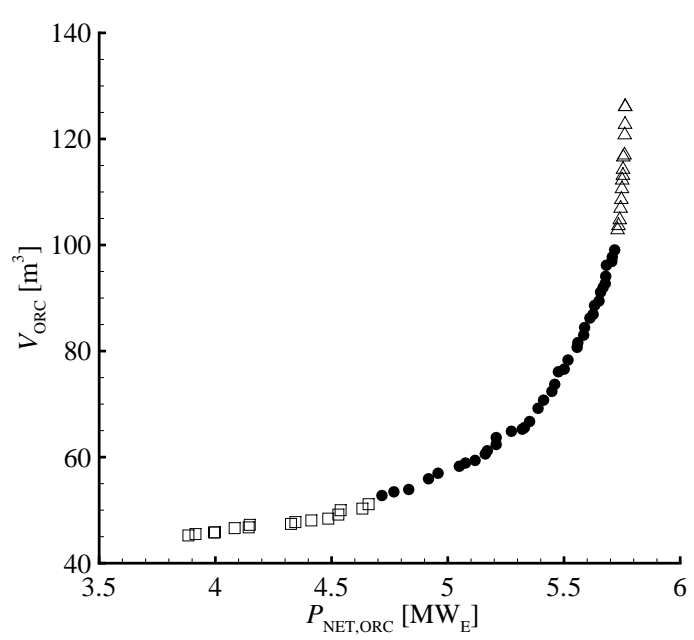

(a)

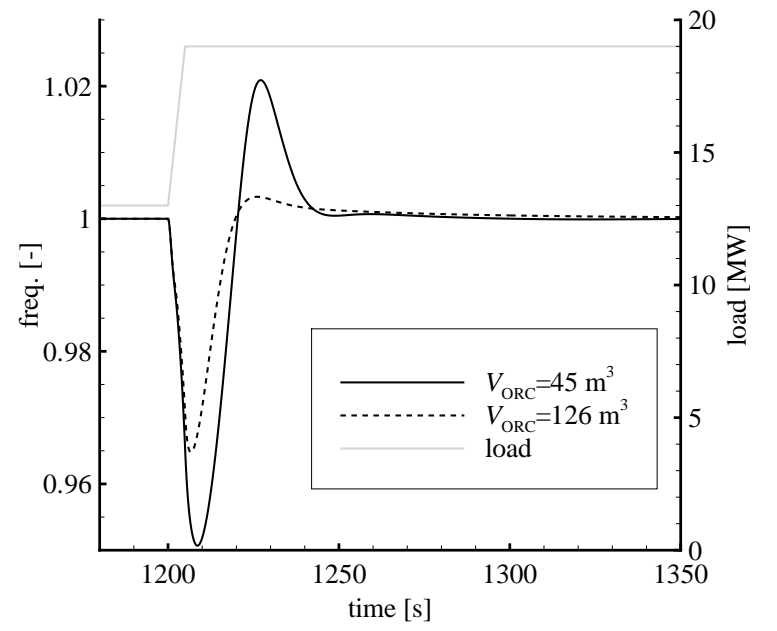

(b)

Figure 8: 8(a) multi-objective optimization results, Pareto front showing the relation between the objective functions, e.g. the ORC system net power and the volume of the heat transfer equipment $V_{\text {ORC }}$. The designs identified by the $\square$ symbol are discarded due to the unacceptable frequency undershoot, while those marked with $\Delta$ due to volume limitations. The other designs (filled circles) are deemed acceptable. 8(b) results of the dynamic test, the grey line represents the corresponding load variation. Normalized frequency and combined cycle load vs time for the two designs characterized by the maximum and minimum values of $V_{\mathrm{ORC}}$. 


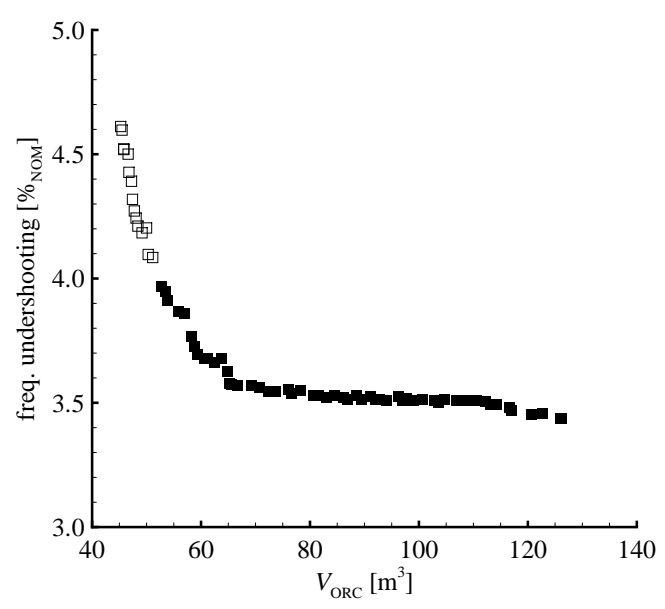

(a)

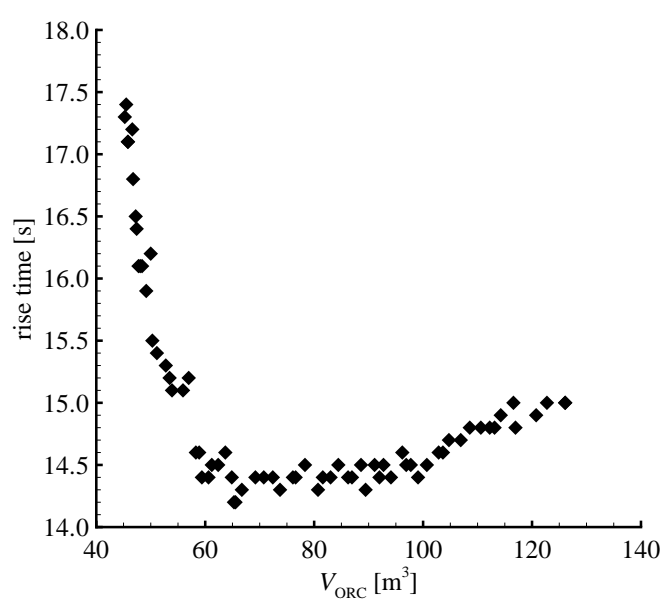

(b)

Figure 9: Results of the dynamic test. 9(a) frequency undershoot vs volume $V_{\mathrm{ORC}}$, all the points of the Pareto front are reported. The designs identified by the $\square$ symbol are discarded due to the unacceptable frequency undershoot $(>4 \%)$. 9(b) rise time vs $V_{\text {ORC }}$, all the points of the Pareto front are reported. 


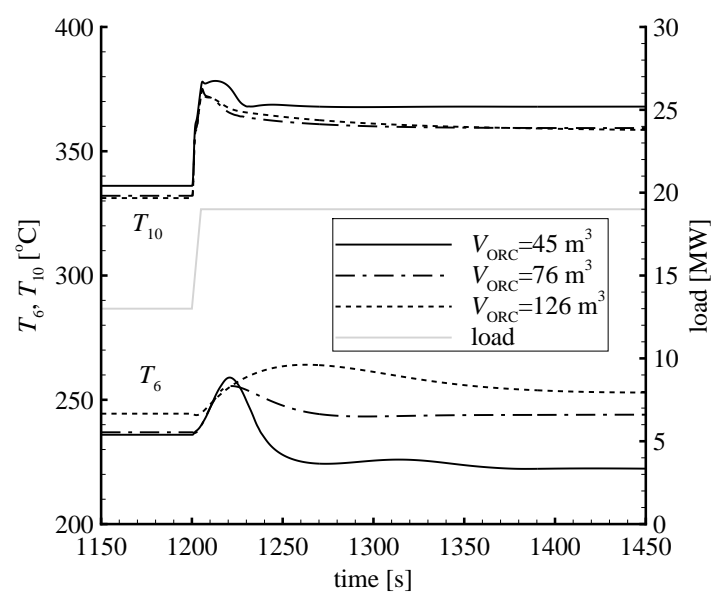

(a)

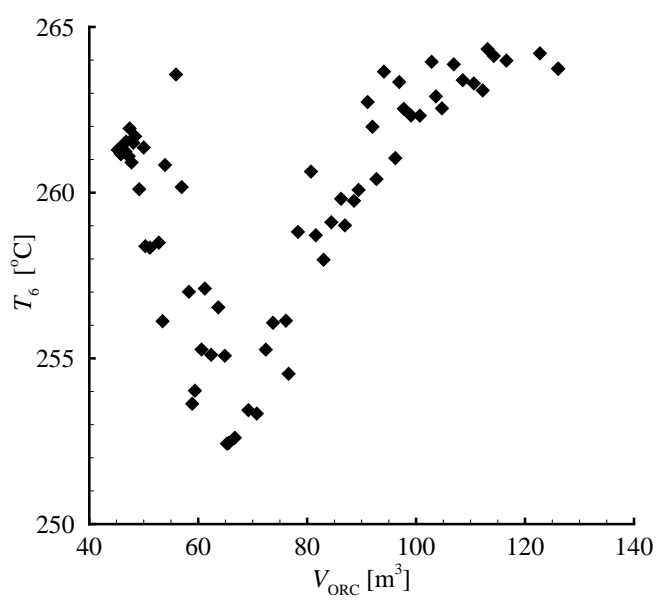

(b)

Figure 10: Results of the dynamic test, the grey line represents the corresponding load variation. 10(a) turbine inlet temperature $T_{6}$, and exhaust gases temperature at the once-through boiler inlet $T_{10}$ vs time for three selected designs corresponding to points of the Pareto front (the two designs characterized by the maximum and minimum volume of the heat exchanging equipment $V_{\mathrm{ORC}}$, together with an intermediate value). 10(b) maximum turbine inlet temperature vs $V_{\mathrm{ORC}}$, all the points of the Pareto front are reported. 
Table 1: Design point specifications for the Siemens SGT-500 industrial twin spool gas turbine installed on the Draugen off-shore oil and gas platform.

\begin{tabular}{lr}
\hline Model & Siemens SGT-500 \\
\hline Turbine inlet temperature & $850{ }^{\circ} \mathrm{C}$ \\
Exhaust gas temperature & $379.2{ }^{\circ} \mathrm{C}$ \\
Exhaust gas mass flow & $91.5 \mathrm{~kg} / \mathrm{s}$ \\
Electric power output & $16.5 \mathrm{MW}$ \\
Thermal efficiency & $31.3 \%$ \\
Fuel & Natural gas \\
\hline
\end{tabular}


Table 2: Results of the thermodynamic states calculation for one exemplary ORC system characterized by a volume

\begin{tabular}{|c|c|c|c|c|c|c|}
\hline Node & $\mathbf{T}\left[{ }^{\circ} \mathrm{C}\right]$ & $\mathbf{p}[\mathbf{k P a}]$ & $\mathrm{h}\left[\mathrm{kJ} \mathrm{kg}^{-1}\right]$ & $\mathrm{s}\left[\mathrm{kJ} \mathrm{kg}^{-1} \mathrm{~K}^{-1}\right]$ & $\mathrm{u}\left[\mathrm{kJ} \mathrm{kg}^{-1}\right]$ & $\rho\left[\mathrm{kg} \mathrm{m}^{-3}\right]$ \\
\hline 1 & 50.0 & 104.0 & 1.4 & 0.004 & 1.3 & 714.9 \\
\hline 2 & 51.4 & 2416.0 & 5.9 & 0.008 & 2.5 & 716.2 \\
\hline 3 & 104.9 & 2416.0 & 117.5 & 0.326 & 113.8 & 657.3 \\
\hline 4 & 193.9 & 2416.0 & 348.4 & 0.871 & 343.6 & 511.4 \\
\hline 5 & 193.9 & 2416.0 & 567.2 & 1.340 & 531.6 & 67.7 \\
\hline 6 & 229.7 & 2416.0 & 659.8 & 1.531 & 614.6 & 53.4 \\
\hline 7 & 143.0 & 104.0 & 535.4 & 1.600 & 486.9 & 2.1 \\
\hline 8 & 74.1 & 104.0 & 423.8 & 1.308 & 383.8 & 2.6 \\
\hline 9 & 50.0 & 104.0 & 390.0 & 1.207 & 353.1 & 2.8 \\
\hline
\end{tabular}


Table 3: Lower and upper bound for the variables of the multi-objective optimization.

\begin{tabular}{lcc} 
Variable & Lower bound & Upper bound \\
\hline Turbine inlet pressure $[\mathrm{bar}]$ & 5 & 41.1 \\
Pinch point recuperator $\left[{ }^{\circ} \mathrm{C}\right]$ & 10 & 40 \\
Temperature difference $\mathrm{OTB}\left[{ }^{\circ} \mathrm{C}\right]$ & 10 & 80 \\
Exhaust gas temperature $\left[{ }^{\circ} \mathrm{C}\right]$ & 140 & 180 \\
Inlet diameter of the tubes $[\mathrm{mm}]$ & 16 & 50 \\
Thickness of the tubes $[\mathrm{mm}]$ & 1.6 & 3.2 \\
Length of the tubes $[\mathrm{m}]$ & 1.83 & 7.32 \\
Tube pitch [-] & 1.1 & 1.3 \\
Baffle spacing $[\%]$ & 20 & 100 \\
Gas velocity $\left[\mathrm{m} \mathrm{s}^{-1}\right]$ & 10 & 70 \\
\hline
\end{tabular}


Table 4: Parameters assumed for the multi-objective optimization.

Parameter
Organic Rankine cycle

Working fluid

cyclopentane

Pump isentropic efficiency [\%]

72

ORC turbine isentropic efficiency [\%] 80

Electric efficiency of the generator [\%] 98

Condensing pressure [bar] 1.04

\section{Once-through boiler}

Layout in-line

Material stainless steel

Longitudinal pitch $[\mathrm{mm}]$ 83

Transversal pitch [mm] 83

Fin pitch $[\mathrm{mm}]$ 1.5

Fin thickness [mm]

Fin height [mm] 24

Fin efficiency [\%] 95

\section{Recuperator}

Layout triangular pitch

Material cupro-nickel

Fin pitch [mm]

Fin thickness [mm]

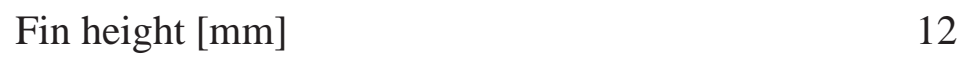

Fin efficiency [\%] 95 
Table 5: Results of the multi-objective optimization. Maximum, minimum, arithmetic mean average, and relative standard deviation of the optimized variables. The values are relative to the 70 points of the Pareto front.

\begin{tabular}{ccccc}
\hline Variable & Maximum & Minimum & AMA & RSD [\%] \\
\hline$p_{6}[\mathrm{bar}]$ & 38.3 & 24.1 & 34.3 & 15.0 \\
$\Delta T_{r}\left[{ }^{\circ} \mathrm{C}\right]$ & 23.0 & 22.1 & 22.6 & 1.0 \\
$\Delta T_{\text {OT B }}\left[{ }^{\circ} \mathrm{C}\right]$ & 58.7 & 43.0 & 52.0 & 12.6 \\
$T_{11}\left[{ }^{\circ} \mathrm{C}\right]$ & 158.6 & 142.7 & 148.1 & 4.2 \\
$d_{i, \text { OTB }}[\mathrm{mm}]$ & 47.0 & 23.5 & 29.9 & 18.8 \\
$t h_{\text {OTB }}[\mathrm{mm}]$ & 3.0 & 1.9 & 2.2 & 11.6 \\
$l_{\text {OT B }}[\mathrm{m}]$ & 6.8 & 5.7 & 6.4 & 5.6 \\
$u_{\text {exh }}\left[\mathrm{m} \mathrm{s}{ }^{-1}\right]$ & 64.2 & 55.6 & 62.5 & 3.5 \\
$d_{i, r}[\mathrm{~mm}]$ & 18.7 & 16.6 & 17.9 & 1.7 \\
$t h_{r}[\mathrm{~mm}]$ & 3.0 & 2.2 & 2.5 & 7.7 \\
$l_{r}[\mathrm{~m}]$ & 4.3 & 3.8 & 4.0 & 3.8 \\
$p t[-]$ & 1.29 & 1.19 & 1.27 & 2.1 \\
$l_{b}[\%]$ & 80.1 & 68.1 & 76.9 & 4.6 \\
\hline
\end{tabular}

